\title{
THOSE WHO DESTROY AND THOSE WHO RECONSTITUTE
}

\author{
By Dr. Luis Subirana, Madrid, Spain. \\ Professor of Orthodontia in the School of Dentistry of the University of Madrid.
}

\begin{abstract}
$\mathrm{O}^{\mathrm{n}}$ RTHODONTIA, in Spain, as well as Europe, is in such a rudimentary state of deveiopment that the writer feels that, even though he reach an extremely old age, he would not see this splendid branch of medicine enjoy its due, social and scientific prestige, consideration and respect necessary for its physiological transcendency in all classes profane and medical, as well as dental. The indifference and ignorance in both classes is so great (it concerns the one because it is to derive the benefits of orthodontia, the other because it is to contribute to the attainment of this object, since the highest mission of the doctor and dentist is to care for the health of humanity) that numberless evils are produced. We say numberless, because we continue to think that the moral and intellectual qualities in man arise in the physical structure and we adjudge to the mouth the greatest vegetative importance for its organs, function and surrọndings.
\end{abstract}

The clinic, the greatest teacher, affords us every day occasions to appreciate the rudimentary state in which orthodontia really is and what it signifies. Today it is the colleague who recommends "not to undertake the regulation until the child is perfectly developed." (These words are repeated so very frequently, that, of course, the professional ethics remain miserably mistreated.) Again, it is a doctor who orders a six-year molar extracted. The other day it was a father who permitted the mutilation and extraction of one or two of his son's teeth in order to have the teeth arranged in harmony.

The case here presented is highly instructive. The child was operated upon in a French town for some growth. In spite of the ablation, the child continued to breathe through the mouth for some months after. Following the advice of the rhinologist, the child was taken to a dentist in Paris and he proposed the correction of the dental range. For the first step he proposed and executed the extraction of the left lower lateral incisor. The following day he was to extract the upper lateral incisor on the same side, which is seen in infra-linguoversion (Fig. 7). The maternal instinct saw a blunder or error in what had been done and proposed by the dentist. Although the one tooth was gone, and no remedy possible, there was still time to save the other. New consultation with the rhinologist. . . .

The girl was eleven years old. She was nervous, extremely sensitive, dull and faint looking. She had a depressed thorax, slant neck, pale face, very thin generally, and had mouth breathing. In criticising the procedure, let us say, as Angle, according to his definition: "Orthodontia is a science, the object of which is to correct the malocclusion of the teeth," and without pretending to excel the great professor, we are going to amplify it, saying: "Orthodontia is that science which, defending the right of the dental system, contributes to the 


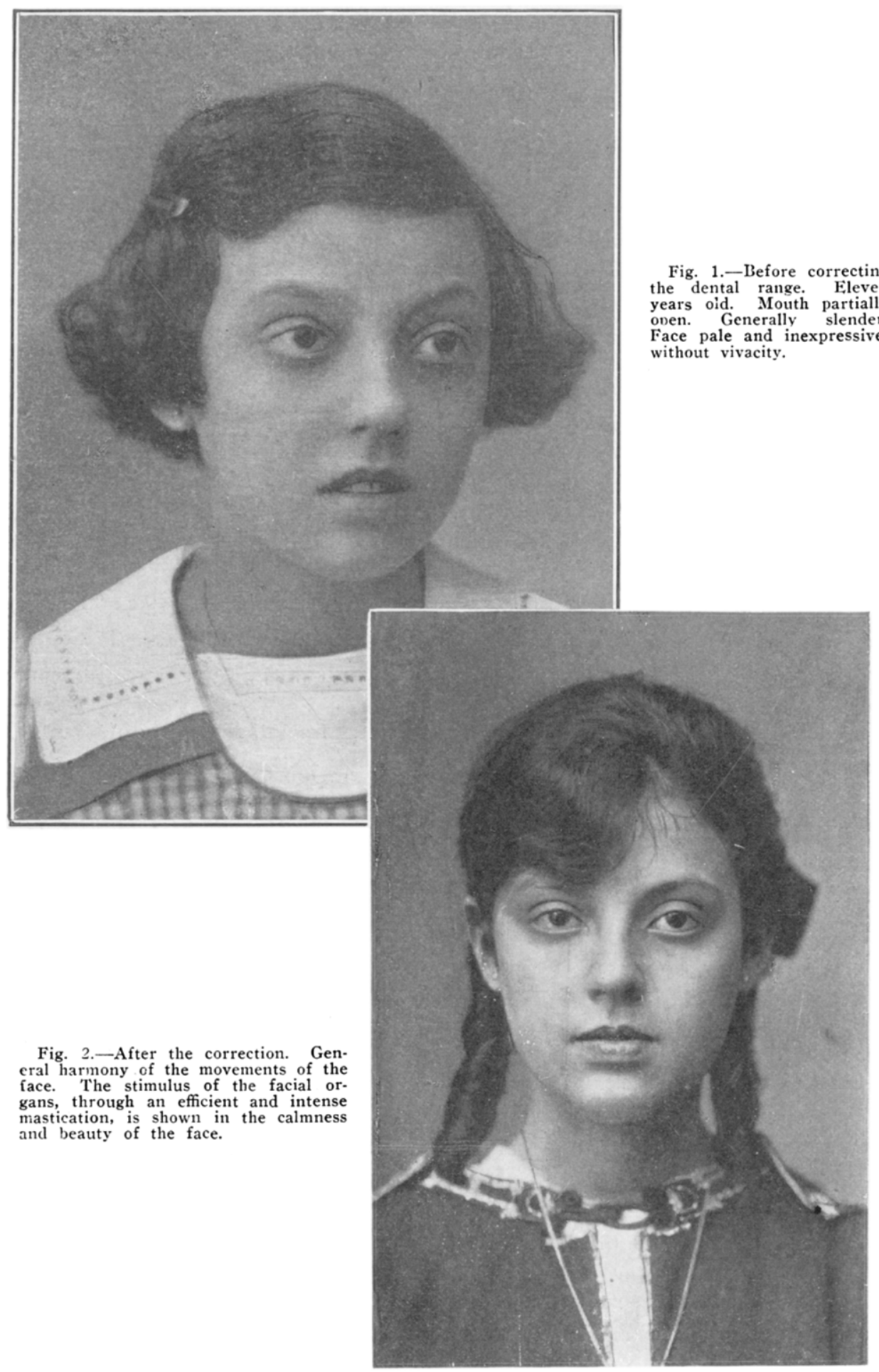




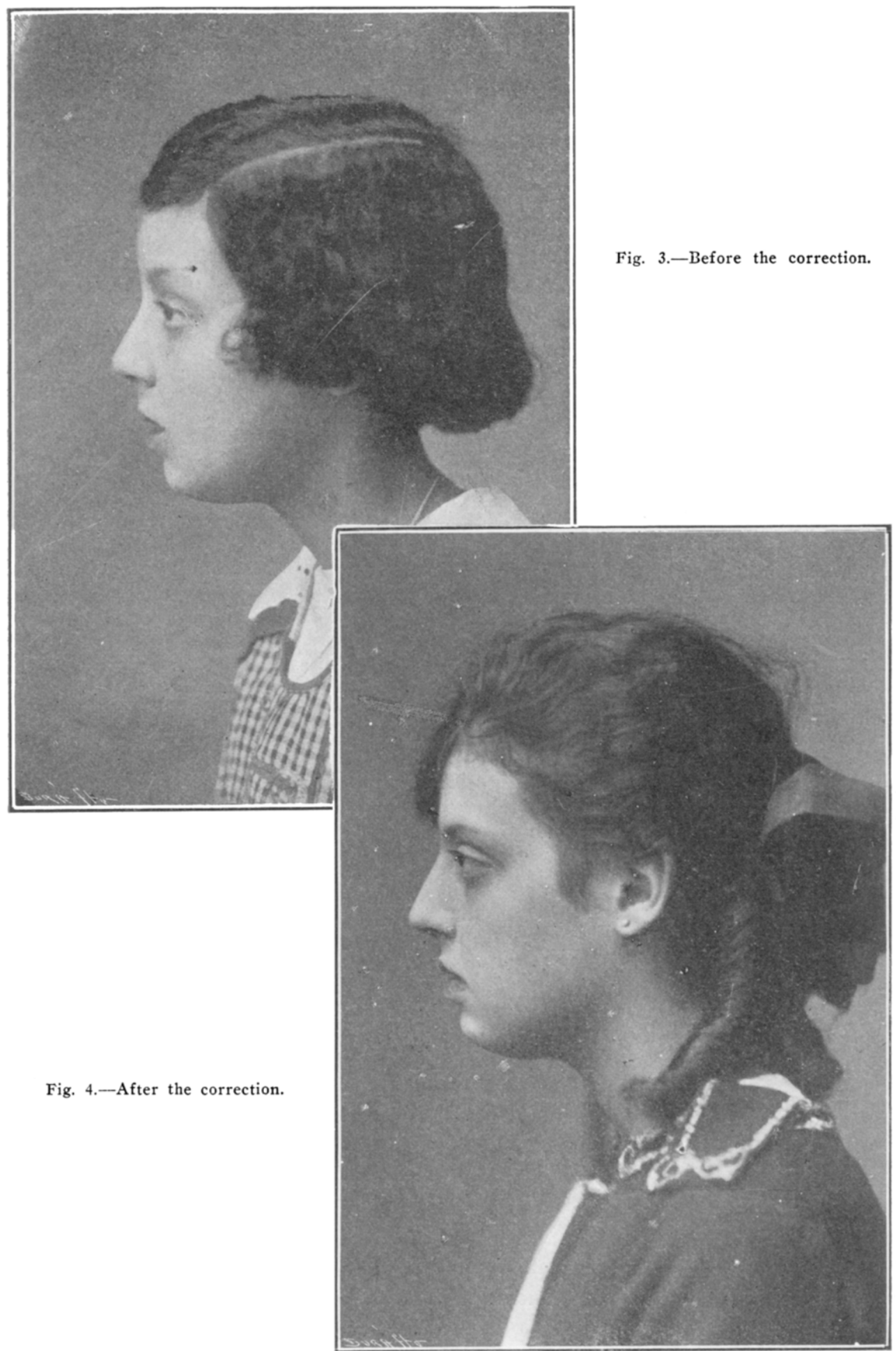


harmonical development of the face, and of the organs integrating it, wholly and regularly assisting the functions of the mouth."

We do not pretend in this article nor at this time to advance a new definition, but simply to explain, and facilitate the comprehension of our successive arguments.

If what Angle and we say is true, and in fact it is, all men who, in order to correct the teeth extract them, continue to separate themselves from the

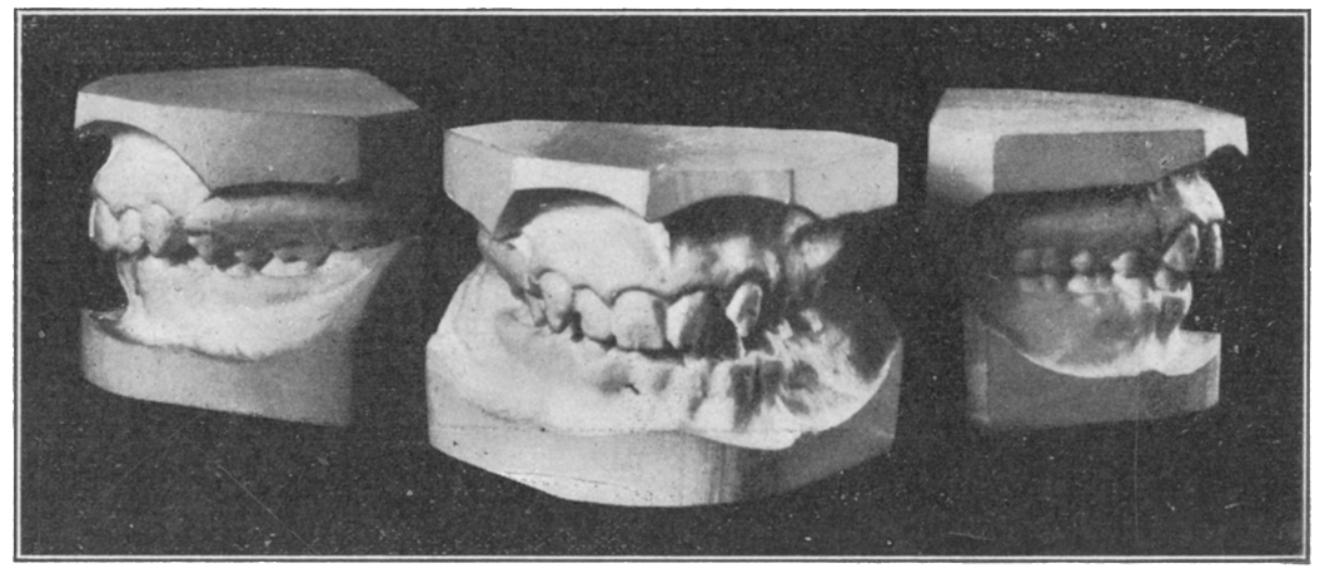

Fig. 5.-Model of the mouth before the correction. Notice that the central and left canines are intact. The lateral one is in the palatinc arch.

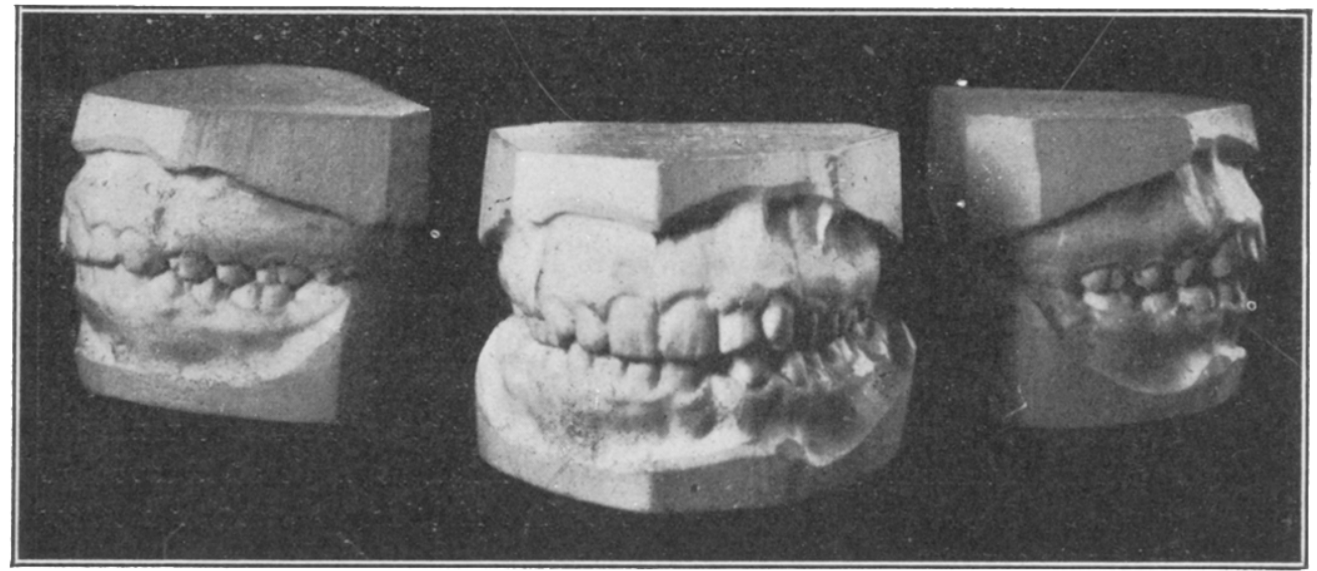

Fig. 6.-Models of the mouth after correction. The occlusion is perfect. The left superior lateral stands in a right line. In the model one may see the space obtained to secure the corresponding length of the arch; a space which will be occupied by a false tooth, rectifying the harm caused by the extraction.

noble aims of orthodontia the more they extract, because orthodontia is not that sum of operations, manipulations, opinions, and personal subjective thoughts, which have for their object the adjustment of a few stray teeth in the mouth. Orthodontia is something much more serious. It is something that does not permit personal interpretations. A malocclusion is not a disputable thing. Orthodontia has its canons, its laws. It is a regulated and measured thing, and he 
who forget's nature's institutions goes directly against the aims of orthodontia.

In the philogenical regulation man has 32 teeth. The orthodontist's duty is to respect this sacred accommodation for the necessities of man. He who injures them, betrays this duty, more than that, he makes the first step of

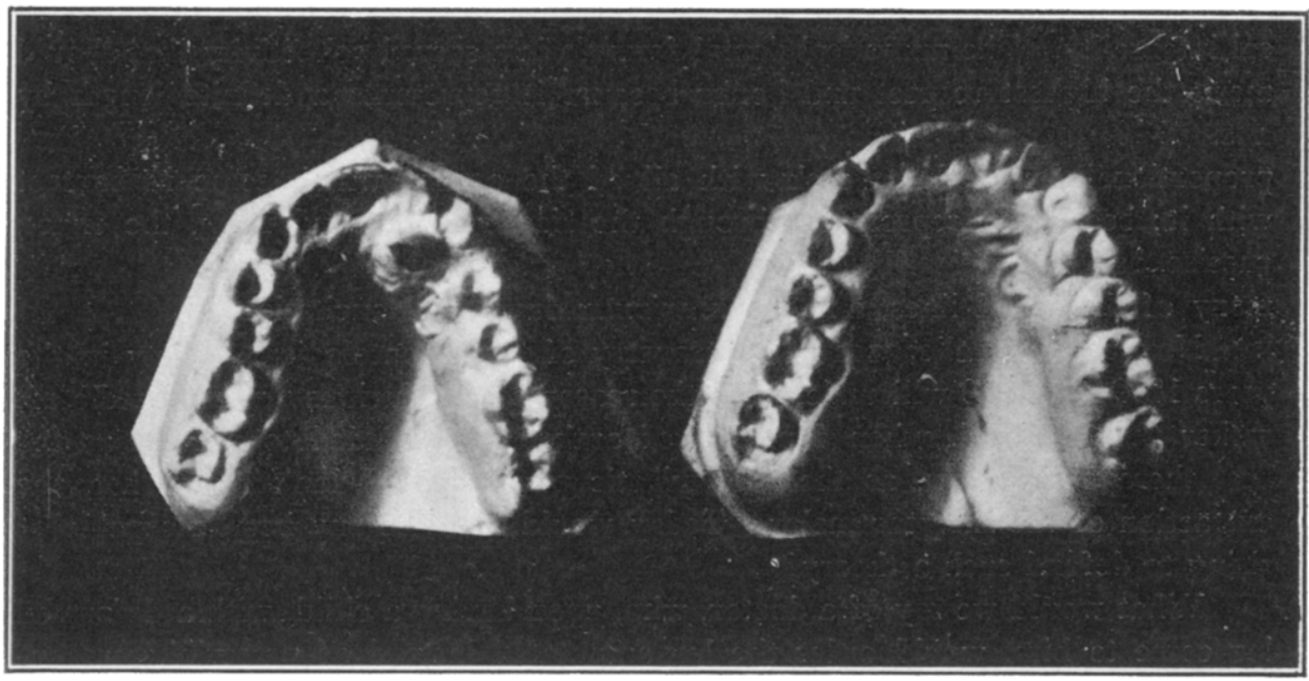

Fig. 7.-Occlusal suriace before the correction.

Fig. 8.--Occlusal surface after the correction.

Let us compare the enlargement of the palatine and dental arches with their symmetry. In Fig. 7 one sees the lateral incisor in intraversion, rendering difficult phonation. In Fig. 8 it is seen in its anatomical position.

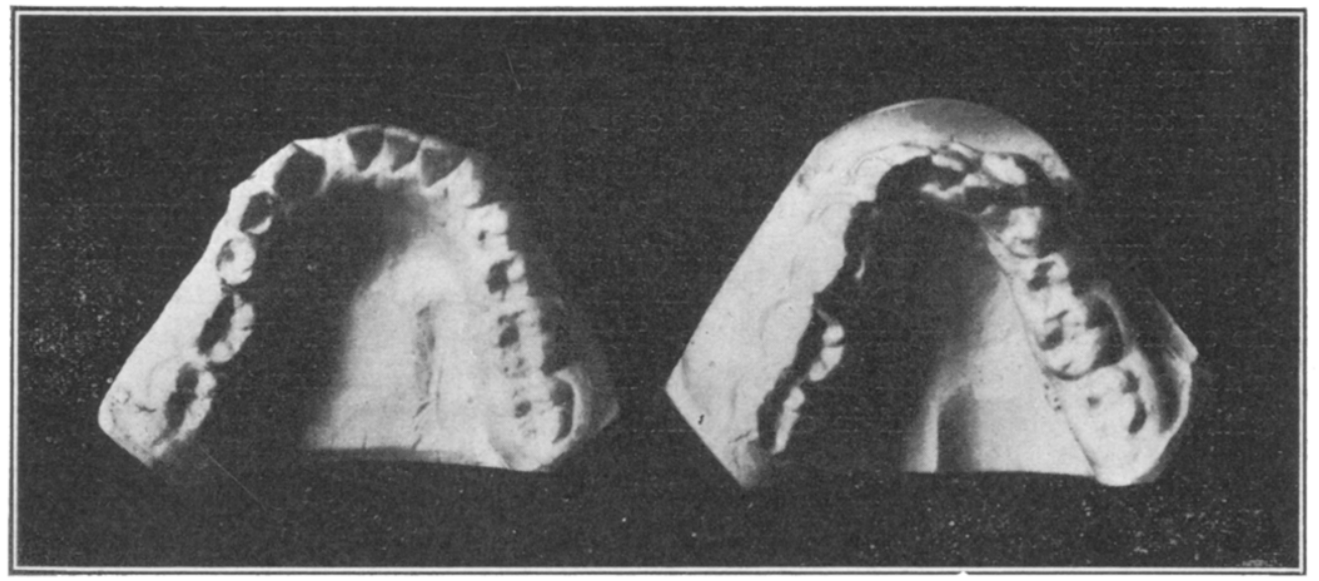

Fig. 9.-Occlusal surface after correction.

Fig. 10.--Occlusal surface before correction.

More than one centimeter of enlargement was secured which has afforded the tongue a "lodging" in proportion to its size. Fig. 9 shows the space secured for the lateral incisor.

individual degeneration, which, if continued during successive generations, will corrupt the species.

When a child, having a malocclusion, comes to our consultation to have 
some dental relation corrected, he does not come to have the number of teeth corrected. The orthodontist is the guider of deviations, not a surgeon to cure by maiming.

The blood and wound should be proscribed to the orthodontist. The orthodontist is the orthopedist who, realizing the inestimable value of the living matter corrects, modifies and reinstates the functional integrality within the anatomical integrality. The numerical dental formula is a sacred collectivity that should merit the highest respect and honor because it represents a definite length by a sum of antero-posterior diameters; because it represents an adequate. and proportional form of the arch with all of the organs which come in contact with it; because it represents, through the size, relation, and form, the exact, precise, and harmonical limit for the phonation, mechanics of digestion, the harmony of the facial lines, and the maximum functional excitation.

Now my old colleagues of controversy of the Odontological Society in the years 1899 and 1900 will understand the reason of our furious protest, predicted, rather than rational, when a person of authority pretended to present as the best therapeutical law, as the prophylactic panacea of I-don't-know-what, the extraction of the six year molar. Today would there be any heretic capable of rising to defend such a theory?

What would we say of a doctor, who, upon having a child, with a deformed leg come to him, would order the leg amputated instead of prescribing reconstituents and orthopedic therapeutics. It is the same case.

A malocclusion is neither an illness nor a wound; it is an anomaly. It is a perversion of a union of the organs in geometrical solidarity. It is a system accidentally out of order, and its normal state must not be secured by the suppression of one of its elements, factors or its unities.

Therefore, our method of procedure was contrary to the former one. It was necessary to preserve the superior lateral. It was also necessary to enlarge, to space the lower teeth, and to obtain a space of equal diameter to the extracted lower tooth, in order to insert a false one. Without this requisite, orthodontia would not be possible. Only with orthodontia could "normal occlusion" be obtained the basis of coordination and correlation, and anatomical harmony of all the muscles and bones that are below its statical and dynamic dependency. We do not pretend to speak of the technic followed in this correction and of the other considerations, which will be given the proper space. We have simply endeavored to show with this case the necessity of preserving the number of teeth, a point so essential in orthodontia. 